\title{
С.Л. Буковский
}

Российский университет транспорта,

127994 г. Москва, Российская Федерация

\section{Методические приемы \\ и комплекс упражнений \\ креативного обучения \\ при подготовке к реферированию \\ иноязычных текстов в неязыковом вузе}

Статья посвящена разработке методических приемов и комплекса упражнений в соответствии со спецификой креативного обучения иноязычному реферированию иностранных текстов на занятиях по иностранным языкам в неязыковом вузе. Дается детальный анализ теоретических и практических основ предлагаемого автором креативного обучения, представленного комплексом упражнений. Автором предложен алгоритм последовательных действий со стороны преподавателя и учащихся, представлены методических приемы, которыми должен руководствовать преподаватель при использовании данных упражнений. Целью статьи является оптимизация процесса обучения иностранным языкам в вузе в виде разработки методических приемов и упражнений креативного формата обучения с целью материализации новаторского методического подхода с позиции креативно-экзистенциального формата обучения иностранным языкам в вузе.

Ключевые слова: неязыковой вуз, обучение иностранным языкам, говорение, методические приемы обучения, комплекс упражнений, реферирование текста, креативное мышление, речевые упражнения, алгоритм обучения, этапы обучения 
ССЫЛКА НА СТАТЬЮ: Буковский С.Л. Методические приемы и комплекс упражнений креативного обучения при подготовке к реферированию иноязычных текстов в неязыковом вузе // Педагогика и психология образования. 2020. № 1. C. 45-58. DOI: 10.31862/2500-297X-2020-1-45-58

DOI: $10.31862 / 2500-297 X-2020-1-45-58$

\title{
S. Bukowski
}

\author{
Russian University of Transport, \\ Moscow, 127994, Russian Federation
}

\section{Methodical techniques and exercise system for creative learning in preparation for abstracting foreign texts in a non-linguistic university}

The article is devoted to the development of methodological techniques and exercise system in accordance with the specifics of creative training in foreign language abstracting of foreign texts in foreign language classes at a non-linguistic university. The author gives detailed analysis of the theoretical and practical foundations of the creative training proposed by the author, represented by a set of exercises. The author proposed an algorithm for sequential actions on the part of the teacher and students, presented methodological techniques that the teacher should apply when using these exercises. The aim of the article is to optimize the process of teaching foreign languages at university in the form of developing methodological techniques and exercises for a creative teaching format in order to materialize an innovative methodological approach from the perspective of a creative existential format for teaching foreign languages at university.

Key words: non-linguistic university, foreign language teaching, methodical techniques, exercise system, text summary, speaking, creative thinking, communicative exercises, teaching algorithm, teaching stages

CITATION: Bukowski S.L. Methodical techniques and exercise system of creative thinking teaching for foreign language texts summarizing preparation in nonlinguistic university. Pedagogy and Psychology of Education. 2020. No. 1. Pp. 45-58. (In Russ.) DOI: 10.31862/2500-297X-2020-1-45-58 
Актуальность данной статьи обусловлена необходимостью новаторства современной методики обучения иностранным языкам в вузе с интегрированным использованием теоретических аспектов экзистенциальной психологии. Научная новизна статьи заключается в создании методических приемов и комплекса упражнений на основе синтеза интеграции психолого-диагностирующих средств в методику обучения иностранным языкам, формирующих новый подход в обучении иностранным языкам в рамках вузовского профиля. Научно-прикладное значение статьи обусловлено возможностью практического применения разработанного автором статьи экзистенциально-креативного подхода в обучении иностранным языкам в соответствии с концепцией его содержания.

\section{Особенности обучения иностранным языкам в неязыковом вузе}

Обучение иностранным языкам в неязыковом вузе имеет свою специфику. Среди факторов, осложняющих процесс обучения, можно назвать следующие:

а) дисциплина «Иностранный язык» не является профилирующим предметом, что часто становится причиной снижения уровня мотивации студентов к изучению иностранного языка;

б) ограниченное количество часов, отводимых на изучение языка, создает сложности для преподавателя в распределении учебных материалов, в использовании необходимых методов и приемов, в определении целей и постановке конкретных образовательных задач;

в) профессиональная ориентация лексического материала осложнена незакрепленной общеобразовательной лексикой обучающихся, недостаточное знание которой сказывается на выполнении определенных речевых заданий.

И.М. Берман, в свою очередь, выделяет такие особенности обучения иностранному языку в неязыковом вузе, как:

а) практическая направленность обучения. Обучение языку в неязыковом вузе отличается четкой практической направленностью и предметностью. Студенты овладевают языком, прежде всего, как средством для получения дополнительной информации по своей специальности;

б) преемственный характер обучения. Будучи продолжением школьного обучения, втузовский курс опирается на знания, умения и навыки, приобретенные обучающимися в школе;

в) высокая степень обобщенности. Качественное своеобразие обучения в неязыковом вузе состоит в том, что полученные знания по языку на основе обобщений формируются в направленную функциональную систему;

г) повышение удельного веса самостоятельной работы [2, с. 48-51]. 
Данные аспекты специфики обучения осложняют процесс обучения говорению, включая задания, связанные с реферированием иноязычных текстов, что, в свою очередь, считается одним из самых сложных условно-речевых заданий в неязыковом вузе.

Трудности обучения иноязычному говорению неоднородны и, как правило, связаны с проблемами:

а) организационного характера: недостаток учебного времени, необходимого для формирования умений в диалогической и монологической речи;

б) учебного характера: недостаточные активность, самостоятельность, интерес, внимание, целеустремленность обучающихся;

в) психолингвистического характера [6, с. 227].

В связи с этим преподаватель, приступая к планированию педагогического процесса, должен в первую очередь:

1) четко определить, какой метод обучения целесообразно использовать в данных условиях, учитывая его основные принципы и положения;

2) обеспечить соответствие отбираемого учебного материала целям и задачам обучения;

3) определить характер, последовательность и взаимообусловленность приемов, которые будут использоваться в обучении [2, с. 16].

\section{Особенности подготовки студентов к выполнению речевых и условно-речевых заданий}

Перечисленные выше сложности нередко возникают при выполнении речевых и условно-речевых заданий. В частности, студенты неязыковых вузов «традиционно» испытывают затруднения именно с реферированием текстов, а также при выполнении заданий дискуссионного характера, требующих от обучающихся активного продуцирования иноязычной речи. Иными словами, студенты должны уметь демонстрировать не только подготовленную, но и неподготовленную устную иноязычную речь.

Как утверждает Б.А. Лапидус, с точки зрения подготовленности или неподготовленности целесообразно различать не два, а три вида высказываний:

а) экспромтные, или неподготовленные, высказывания;

б) заученные высказывания, когда текст-оригинал воспроизводится обучающимся практически наизусть;

в) незаученные подготовленные высказывания, когда студент заранее продумывает структуру и содержание своего выступления, но конкретные предложения формирует в момент говорения (подобные высказывания можно наблюдать у докладчиков и лекторов, которые не читают 
полный написанный текст, а импровизируют в соответствии с ситуацией) [5, с. 20-21].

В этой связи на практике возникает ряд методических просчетов со стороны преподавателей, предлагающих студентам заучивать наизусть иноязычные реплики, фразы, фрагменты из текстов и диалогов. Предлагая студентам заучивать наизусть те или иные отрывки текста, сторонники данного вида упражнений, видимо, надеются, что отдельные фрагменты (слова или фразы) будут использованы обучающимися в дальнейшем. Однако такая позиция ошибочна. Ведь в естественной ситуации каждый акт речи - это продуцирование какого-то нового содержания. Он соответствует данной ситуации общения в данных условиях среды и никогда в точности не повторяется. В этом смысле речевой фрагмент, который был использован в «своей» ситуации общения, вряд ли сможет найти применение в других обстоятельствах [1, с. 62].

Тезис о непродуктивности заучивания наизусть универсален и не зависит от характера текста: заучивание наизусть диалога столь же малопродуктивно, как и заучивание монологического отрывка [Там же, с. 63].

\section{Методические приемы при формировании креативных навыков}

Автором настоящей статьи разработан алгоритм методических приемов, используемых при формировании креативных навыков, отвечающих за появление и активизацию дивергентного мышления при решении учебной задачи. Алгоритм включает в себя креативную установку, процессуальный этап, этап креативизации сознания и выход к пересказу текста (табл. 1).

Креативная установка, которую дает преподаватель путем объяснения конвергентно-дивергентной дифференциации, заключается в разделении конвергентного (логического) и дивергентного (креативного) мышления. Процессуальный этап предполагает использование креативно ориентированных тренировочных заданий. Этап креативизации сознания предусматривает самостоятельное формулирование обучающимися креативной задачи и ее экстраординарное решение. Таким образом, студент, прежде чем приступить к реферированию текста, должен получить креативную установку (объяснение преподавателем необходимости конвергентно-дивергентной дифференциации), пройти процессуальный этап (выполнение креативных заданий с целью формирования креативных навыков мыслительной деятельности и дивергентного восприятия) и этап креативизации сознания (самостоятельного формулирования креативной задачи и ее выполнения), и только после этого он переходит к подготовке пересказа текста. 
$\frac{7}{3}$

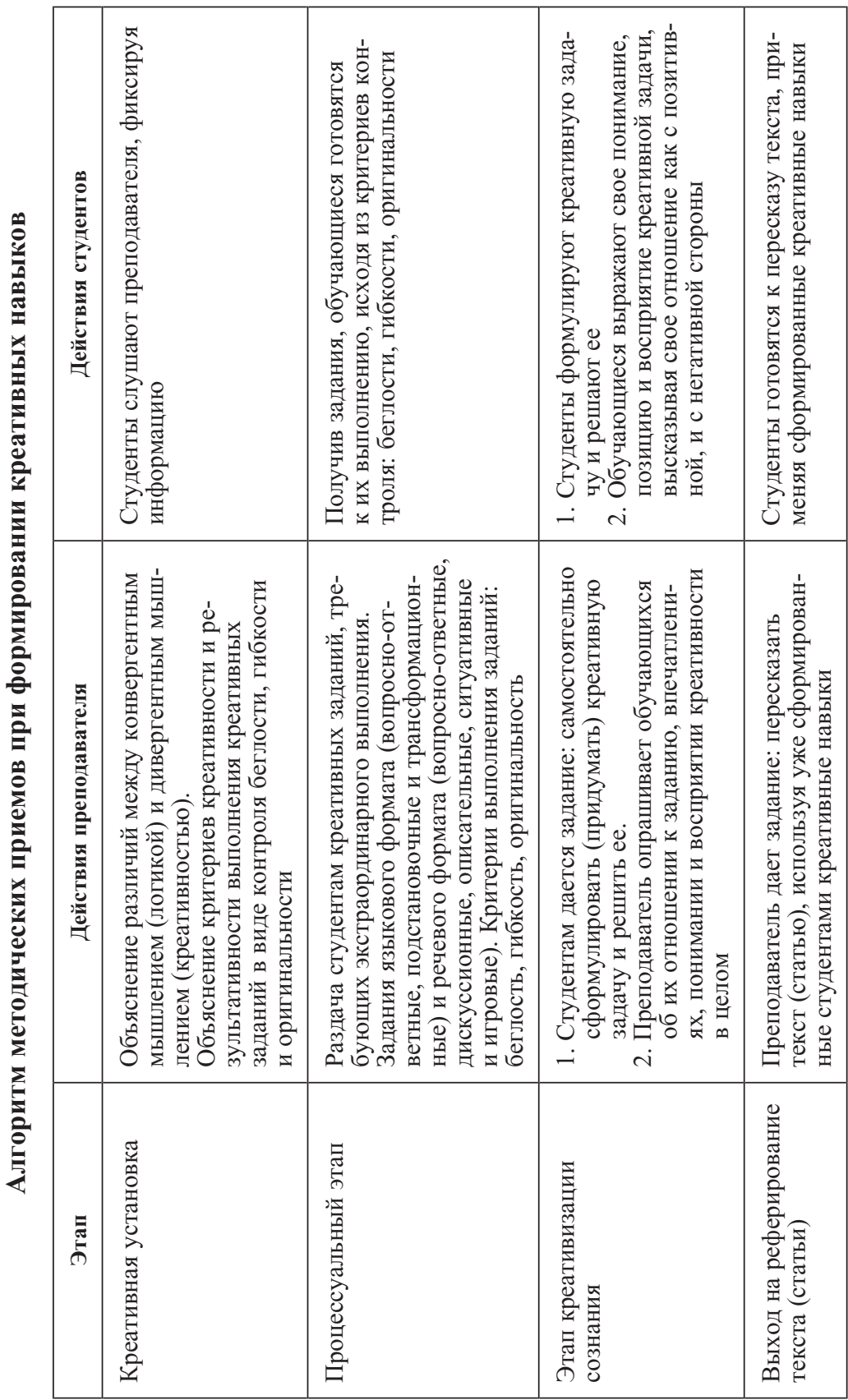


Представленный алгоритм активно используется студентами на практике, хотя до сих пор не имеет методического обоснования и широкого применения на занятиях по иностранным языкам в неязыковом вузе, где подготовка к данному заданию либо носит хаотичный характер по принципу «кто как может, так и готовится», либо студенты заучивают наизусть выделенные преподавателем фрагменты текста. В первом случае студент, предоставленный самому себе, не имеет четко выраженной методической установки со стороны преподавателя, во втором - установка, данная преподавателем, носит дисфункциональный и ложный характер, поскольку воспроизведение заученных наизусть фрагментов текста нельзя назвать подлинным пересказом, это всего лишь дословное цитирование.

Реферирование же представляет собой более сложное речевое воспроизведение, требующее использования в устной передаче содержания текста собственных речевых высказываний и самостоятельно построенных грамматических конструкций, а также вводного лексического материала. В связи с этим заучивание наизусть с целью последующего цитирования важно не путать с подлинным пересказом, т.е. с комплексным речевым воспроизведением.

Подобное деление носит концептуальный характер, поскольку детерминация сущности пересказа как задания влияет на детерминацию подготовки к нему, что, в свою очередь, приводит к негативному результату его выполнения. Ключевую роль здесь играет методическая установка преподавателя, которая является базовым индикатором качества выполнения задания.

\section{Подготовка к устному реферированию текста}

Автор настоящей статьи предлагает следующий алгоритм подготовки студентов к выполнению устного реферирования текста, который, исходя из вышеупомянутого методического алгоритма, можно представить в виде нескольких шагов.

Шаг 1. Креативный анализ текста. Данный анализ представляет собой дивергентное восприятие обучающимся текста. Получив незнакомый текст, студент воспринимает его содержание, используя креативное мышление, т.е. воспринимает слова и предложения с позиции ассоциативной связи при активизации воображения.

Ш а г 2. Оглавление частей текста. Мысленно разделив текст на части (в среднем на три), студент мысленно озаглавливает их (буквально одним-двумя словами, чтобы не забыть содержание текста и последовательность информации). Например: первая часть - определение экономики, вторая - виды экономики, третья - функции экономики и т.д. 
Шаг 3. Процессуализация. Мысленно озаглавив части текста, студент приступает к подготовке их устного изложения с использованием вводных слов, словосочетаний, фраз (thus, therefore, in my opinion, this text contains, we arrived at the following observation, in conclusion и т.д.).

Ш а г 4. Подведение итогов. В завершение устного изложения содержания текста студент может выразить свое отношение к проблематике в тексте (согласие или несогласие с отдельными аспектами информации в тексте, свое впечатление), привести дополнительную информацию по теме и т.д.

\section{Комплекс упражнений}

\section{креативно-ориентированного обучения}

устному профессиональному общению в неязыковом вузе (на примере экономического профиля)

Данные упражнения приведены в работах автора [3; 4].

\section{Вопросно-ответные упражнения № 1, 2}

При выполнении упражнений № 1 и 2 студент дает оригинальный ответ на английском языке. Поскольку задание не предполагает конкретного однозначного ответа, то любой ответ обучающегося считается правильным. Упражнения № 1 представлены в виде вопросов, упражнения № 2 сформулированы в виде незавершенных ответов на вопросы задания.

Цель заданий: развитие креативного мышления студентов и его компонентов (беглость, гибкость, оригинальность), способствующих дальнейшему формированию лексических и грамматических навыков, а также развитию речевых умений в области аудирования и говорения.

Примеры вопросно-ответных упражнений № 1

\section{Ex. 1. Answer the questions orally:}

1. What does "deficit" mean?

2. Why do civil servants have a right to buy your land for building of roads, even if you don't want to?

3. What does "to predict" mean?

4. What does "intensification" mean?

5. What is the difference between "plutocracy" and "theocracy"?

6 . What does "logical reasoning" mean?

7. What does "happy end" mean?

8. What does "fifty-fifty" mean?

9. What does "know-how" mean?

10. What does "intensive" mean? 


\section{Примеры вопросно-ответных упражнений № 2}

\section{Ex. 2. Answer the following questions:}

1. I would like to be more like

2. I wish my father (brother, sister, mother) would

3. I wish I could learn

4. We have too many

5. If only we (I) could

\section{Подстановочные упражнения № 3, 4, 5}

Упражнения № 3 состоят из выписанных в столбик слов из лексики данного урока. Задача студента - привести слова, соответствующие (по его мнению) данным словам, преобразовывая их в словосочетания. Здесь также любой вариант ответа студента будет считаться правильным.

Упражнения № 4 представлены в виде таблиц, где приведено несколько близких по значению слов (существительные, глаголы, прилагательные, причастия и т.д.). Задача студента - подобрать одно слово, интерпретирующее и объединяющее по смыслу все перечисленные слова в каждой ячейке таблицы.

В упражнениях № 5 задания состоят из нескольких прописных букв, напоминающих аббревиатуру. Задача студента - придумать предложение, включающее слова, которые начинались бы с этих букв и соответствовали лексике данного урока.

Цель подстановочных упражнений - развитие креативного мышления студентов и его компонентов (беглость, гибкость, оригинальность), способствующих дальнейшему формированию лексических и грамматических навыков, а также развитию речевых умений в области аудирования и говорения.

\section{Примеры подстановочных упражнений № 3}

Ex. 3. Find, as much as you can, definition for the following words. Explain your decision:

For example: book - beautiful book.

1. Production

2. Cooperation

3. Industrialized

4. Government

5. Achievement 
Примеры подстановочных упражнений № 4

Ex. 4. Give the answers interpreting following words.

\begin{tabular}{|l|l|}
\hline \multicolumn{1}{|c|}{ Words } & Responses \\
\hline Rising, falling, equilibrium & \\
\hline Forestry, animal farming, crop farming & \\
\hline White, blue, red & \\
\hline The European Union, The United Nation & \\
\hline Wholesale, retail & \\
\hline Political, economical, social & \\
\hline
\end{tabular}

Example: rising, falling, equilibrium - price.

Примеры подстановочных упражнений № 5

Ex. 5. Make your own sentences based from four words, in which every word begins with the following letters:

Example: D...A......-Demand And Supply.

1. T...O...D...

2. T...O......

3. D...A...P...

4. G...R...O...D...

5. C...T...P.....

\section{Описательные упражнения № 6}

Представлены в виде рисунков из тестов-«батарей» по психодиагностике П. Торранса и в виде «чернильных пятен» теста Г. Роршаха.

Цель упражнений - сформировать креативное мышление студентов, активизировать их деятельность и самостоятельность при выполнении коммуникативных упражнений, в частности репродуктивных, дискутивных, композиционных.

Перед студентом рисунок. Задача студента - объяснить, интерпретировать данное изображение. Любой ответ студента считается правильным. Студент, интерпретируя устно изображение, использует изученный лексический материал и пройденные грамматические конструкции, активизируя тем самым приобретенные навыки и умения в устном общении. 


\section{Cитуативные упражнения № 7}

Данные упражнения представлены в виде вопросов в сослагательном наклонении. Любой ответ студента является правильным. Контроль преподавателя ведется по категориям (беглость, гибкость, спонтанность, оригинальность).

Цель ситуативных упражнений - развитие креативного мышления студентов, активизация и самостоятельность деятельности студентов при выполнении коммуникативных упражнений, в частности репродуктивных, дискутивных, композиционных.

\section{Примеры упражнений № 7}

\section{Ex. 7. Answer the following questions:}

\section{YOU, THE MAGICIAN}

Sometimes, when things aren't going the way we'd like them to go, it seems to us that it would be mighty handy if we could change the world a little. In this exercise you'll be given an opportunity to imagine that you can change things the way you'd like to have them be. If you had magic powers, what things would you change?

1. What would taste better if it were sweeter?

2. What would be more satisfying if it were nearer?

3. What would be more valuable if it could float?

4. What would be nicer if it were smaller?

5 . What would last longer if it were elastic?

6. What would be more fun if it were faster?

7. What would be more refreshing if it were green?

8 . What would be more useful if it were lighter?

Ex. 7. Imagine that you'll have a free day tomorrow, or a holiday next week, what would you do? Discuss (the situation) this pleasant fact.

\section{Ex. 7. In which situations can you use the following sentences:}

I have never heard that before. You leave me no choice. Should I?

\section{Дискутивные упражнения № 8}

Представлены в виде вопросов, подготовленных студентом по тематике пересказанного им текста, с целью обсуждения содержания текста с другими студентами. 
Цель упражнений - формирование умений и навыков монологической и диалогической речи, снижение языкового барьера, развитие коммуникативной активности.

\section{Примеры дискутивных упражнений № 8}

\section{Ex. 8. Forecasting}

Every decision is based on some kind of forecast about the future. The more accurate the forecast (or the smaller error), the better would be the decision. Decide whether you are a good forecaster.

1. Do you usually consider any possible future occurrences that might upset existing conditions? Do you do it mechanically?

2. Do you turn all the information into predictions?

3. Do you manage uncertainty by using effective forecasting?

4. Do you recognize the possible problems and try to overcome them?

\section{Композиционные упражнения № 9}

Представлены в виде заданий, состоящих из подготовки доклада студентом по тематике пересказанного им текста.

Цель упражнений - формирование умений и навыков устной монологической речи.

\section{Примеры композичионных упражнений № 9}

\section{Ex. 9. Requesting suggestions and ideas}

During the meeting the European Commercial Manager needs to get the opinions and suggestions of the two Marketing Managers about the structure of the new marketing department. He does this in several ways.

a) An open request

I'd like to hear some of your suggestions.

b) A question directed at one person

What's your reaction to that?

c) A request for confirmation of his own opinion

Don't you think that your three division structure might be more expensive to operate?

Other phrases that can be used here are:

I'd like to hear your ideas on this.

How do you think we should do this?

What do you recommend? 
What's your opinion?

How do you see this?

\section{Ex. 9. Write an essay using the terms from the vocabulary Macroeconomics.}

\section{Репродуктивные упражнения № 10}

Представлены в виде текстов, объем которых увеличивается с каждым последующим уроком. Это собственно коммуникативные задания, которые служат тренингом для закрепления предыдущих креативных упражнений. Задача студента - пересказать текст.

Цель упражнений № 10 - тренировка выполнения коммуникативных, репродуктивных заданий, текстов экономического содержания.

\section{Примеры репродуктивных упражнений 10}

\section{Ex. 10. Read and summarize the following text}

\section{What is Tax?}

Before considering the basic principles of International Taxation, we need to make sure we know what a tax is. James (1998), in his Dictionary of Taxation, provides a commonly used definition:

A compulsory levy made by public authorities for which nothing is received directly in return'.

This definition suggests that the nature of a tax is that it is a payment made, (a cost incurred) without the usual associated receipt, normal to other transactions, of any consideration in return. The word 'directly' used in the definition is of course important. A government will charge its citizens, and businesses trading within its borders, tax in order to raise revenue to fund the provision of the public sector. Most taxes paid however, are not directly associated with a public sector provision the taxpayer will receive in return but are more loosely linked to the idea of benefits they gain from their link with that country. For example, their taxes will help support economic stability, the availability of a skilled workforce, the physical infrastructure, and so on.

\section{Библиографический список / References}

1. Алхазишвили А.А. Основы овладения устной иностранной речью. М., 1988. [Alkhazishvili A.A. Osnovy ovladenija ustnoj inostrannoj rech'ju [Conception of foreign spoken language acquiring]. Moscow, 1988.]

2. Берман И.М. Методика обучения английскому языку в неязыковых вузах. М., 1970. [Berman I.M. Metodika obuchenija anglijskomu jazyku 
$\mathrm{v}$ nejazykovyh vuzah [English language teaching method in non-linguistic Universities]. Moscow, 1970.]

3. Буковский С.Л. Учебное пособие по английскому языку с упражнениями по развитию креативного мышления. Ч. 1. Для студентов неязыковых вузов. M., 2012. [Bukovsky S.L. Uchebnoe posobie po anglijskomu jazyku s uprazhnenijami po razvitiju kreativnogo myshlenija [Textbook on English with creative-thinking development exercises]. Part 1. Study guide for students. Moscow, 2012.]

4. Буковский С.Л. Учебное пособие по английскому языку с упражнениями по развитию креативного мышления. Ч. 2. Для студентов экономических специальностей. M., 2012. [Bukovsky S.L. Uchebnoe posobie po anglijskomu jazyku s uprazhnenijami po razvitiju kreativnogo myshlenija [Textbook on English with creative-thinking development exercises]. Part 2. Study guide for students. Moscow, 2012.]

5. Лапидус Б.А. Интенсификация процесса обучения иноязычной устной речи (пути и приемы). М., 1970. [Lapidus B.A. Intensifikacija processa obuchenija inojazychnoj ustnoj rechi [Intensification of foreign spoken language education process (ways and methods)]. Moscow, 1970.]

6. Методика обучения иностранному языку: учебник и практикум для академического бакалавриата / Под ред. О.И. Трубициной. М., 2019. [Metodika obuchenija inostrannomu jazyku [Foreign language teaching method]. Textbook and practical work for academic bachelor. O.I. Trubizina (ed.). Moscow, 2019.]

Статья поступила в редакцию 19.09.2019, принята к публикации 02.11.2019

The article was received on 19.09.2019, accepted for publication 02.11.2019

\section{Сведения об авторе / About the author}

Буковский Станислав Леонидович - кандидат педагогических наук; доцент кафедры «Иностранные языки-4» Института транспортной техники и систем управления, Российский университет транспорта, Москва

Stanislav L. Bukowski - PhD in Pedagogy; associate professor at the Department "Foreign languages-4" Institute of Transport Technology and Management Systems, Russian University of Transport, Moscow

E-mail: linguist2019@mail.ru 